\title{
Menumbuhkan Kembali Semboyan "Ngaha Aina Ngoho" Yang Hampir Punah Akibat Krisis Ekonomi
}

\author{
${ }^{1}$ Nurjumiati, ${ }^{2}$ Ulfariani, ${ }^{3}$ M. Salahudin, ${ }^{4}$ Sarnita, ${ }^{5}$ Siti Sarah, ${ }^{6}$ Izzatul Akmalia, ${ }^{7}$ S. Yulianci. \\ ${ }^{1234567}$ STKIP Taman Siswa Bima \\ Email: nurjumiati100@gmail.com
}

\begin{abstract}
Abstrak. Menumbuhkan kembali semboyan "Ngaha Aina Ngoho" yang hampir punah akibat krisis ekonomi sebagai upayya merawat kembali kearifan local bima dalam diri masyarakat terkhususnya anak muda melalui kegiatan sosialisasi dan reboisasi. Program tersebut terlaksana melalui beberapa rangkaian kegiatan maupun persiapan yang bertujuan untuk menghadirkan Kembali kepedulian masyarakat dan anak muda terhadap alam. Selain itu untuk keberlanjutan program ini maka dibentuknya sebuah komunidas yang bernama "pencinta alam" yaitu Gerakan muda-mudi dari desa rora, kegiatan diakhiri dengan penanaman bibit kemiri disalah satu gunung yang tandus dan adanya komunitas ini dapat mewadahi pemuda-pemudi desa rora untuk menjaga kelestarian alam. Semoga kegiatan ini tetap berlanjut dan berjangka panjang. Tujuan jangka Panjang yaitu dengan adanya program menumbuhkan Kembali semboyan "Ngaha Aina Ngoho" ini dapat mengurangi penebangan secara liar, menjaga kelestarian alam, dan menciptakan masyarakat yang sadar akan lingsungan serta kreatif dalam menggunakan SDA sehingga mampu menstabilkan ekonomi warga setempat dan menjadikan desa Rora menjadi desa yang sejahterah dan cinta lingkungan.
\end{abstract}

Kata Kunci: Ngaha ain na ngoho, Krisis ekonomi

\section{PENDAHULUAN}

Belakangan ini, masalah tentang perladangan liar sering terjadi diberbagai daerah dan daerah (Putra, 2018), hal ini dilakukan masyarakat sebagai alternative untuk menanggulangi krisis ekonomi yang dihadapi oleh masyarakat saat ini

Kurangnya lapangan pekerjaan serta minimnya sumber daya manusia (SDM) mengakibatkan tindakan ini terjadi dikalangan masyarakat awam (Manusia, 2004). Maka dari itu kelompok kami akan memulai sebuah langkah dimana cara ini dapat mengembalikan kesadaran masyarakat terkait problematika yang dihadapi oleh pemerintah saat ini.

Seperti yang kita tahu bahwa penebangan liar sangat memprihatinkan bagi kita semua selain merusak ekosistem tindakan ini juga menghilangkan keindahan dari bumi nusantara ini (Salim, 2010). Manfaat dari kegiatan ini sebagai langkah membudidayakan kembali kelestarian alam kita bersama warga setempat.

Pohon yang kita tanam memberikan banyak manfaat bagi seluruh umat manusia (Mursalim, 2018), jika alam hendak kita musnahkan lalu dari mana kita akan mendapatkanan, oleh sebab itu kita harus sama-sama mampu menjaga dan melestarikan alam kita. Salah satu mengembalikan ekosistem hutan kita yaitu dengan mengadakan reboisasi atau menaman kembali, salah satu tanaman yang ditanam dalam kegiatan ini adalah pohon kemiri.

Tanaman kemiri adalah tanaman pohon besar yang yang termasuk dalam tanaman rempah. Kemiri sendiri merupakan tumbuhan yang memiliki banyak manfaat dan memberikan pedapatan yang besar kepada masyarakat. Pohon kemiri (Aleurites moluccana) merupakan pohon yang menghasilkan bahan-bahan industri sejak lama kita kenal. Hampir semua bagian atau produk tanaman ini dapat dimanfaatkan dan memiliki nilai ekonomi (Ismail, 2019). Produksi kemiri bertujuan untuk dikonsumsi dan di ekspor (Koji, 2000).

Biji kemiri tergolong buah batu karena berkulit keras menyerupai tempurung dengan permukaan luar yang kasar berlekuk. Tempurung biji ini tebalnya sekitar 3-5 mm, berwarna coklat kehitaman. Sementara itu 
untuk mendapatkan inti kemiri yang baik dan berkualitas harus disertai dengan penanganan pascapanen yang baik dan benar. Hal yang perlu diperhatikan adalah bagaimana mempertahankan kualitas biji kemiri tersebut. Sedikit saja kecerobohan dalam penanganannya dapat mengakibatkan daging biji hancur dan terkontaminasi cendawan. Untuk menjaga kualitas kemiri, operasi pascapanen harus dikelola secara bijaksana khususnya dalam hal pemecahan biji (Sinaga $\mathrm{dkk}, 2016)$. Lahan yang cocok untuk penanam pohon kemiri adalah lahan yang ketersediaan air yang rendah atau lahan yang kering (Taiyeb, 2017).

Lahan kering beriklim kering perlu mendapat perhatian yang serius khususnya terkait dengan sumber air dan pengelolaannya, mengingat ketersediaan air merupakan faktor pembantas utama akibat curah hujan yang sangat endah. Oleh karena itu, sangat logis jika wilayah lahan kering iklim kering berasosiasi dengan kantongkantong kemiskinan dan menjadi daerah rawan pangan, terutama di NTT dan NTB (Mulyani dkk, 2014). Salah satu daerah NTB yang memiliki lahan beriklim kering adalah kabupaten Bima diantranya di desa Rora.

Dengan pelaksaan kegiatan ini dapat bertujuan untuk menyadarkan kepada seluruh masyarakat yang ada di kota dan kabupaten bima agar kembali melestarikan keadaan alam saat ini yang telah rusak dan tercemar akibat ulah dari masyarakat itu sendiri, sebab akibat keadaan alam yang semakin hari semakin rusak sehingga membuat kita merasakan imbas atau konsekuensi sampai hari ini.

Ngaha Aina Ngoho" dengan beragam makna dan pengertiannya yaitu kita bisa makan dengan menggunakan sumber daya alam yang ada tetapi tidak untuk dihabiskan. kata-kata tidak ntuk dihabiskan di maknai dengan memanfaatkan sumber daya yang ada sesuai dengan kebutuhan bukan berdasarkan kemauan.

Tujuan jangka Panjang dalam kegiatan ini yaitu dengan adanya program menumbuhkan Kembali semboyan "Ngaha Aina Ngoho" ini dapat mengurangi penebangan secara liar, menjaga kelestarian alam, dan menciptakan masyarakat yang sadar akan lingsungan serta kreatif dalam menggunakan SDA sehingga mampu menstabilkan ekonomi warga setempat dan menjadikan desa Rora menjadi desa yang sejahterah dan cinta lingkungan.

\section{METODE PELAKSANAAN}

Untuk pelaksanaan kegiatannya terbuka bagi kalangan mana saja terutama kalangan petani, untuk kegiatannya sendiri dilaksanakan setiap hari sabtu dan minggu yang nantinya akan dipandu oleh tokohtokoh yang menurut kami benar-benar mampu memberikan penyadaran kepada kepada masyarakat. Pelaksanaan kegiatan ini dapat dilaksanakan dalam bentuk kegiatan sebagai berikut:

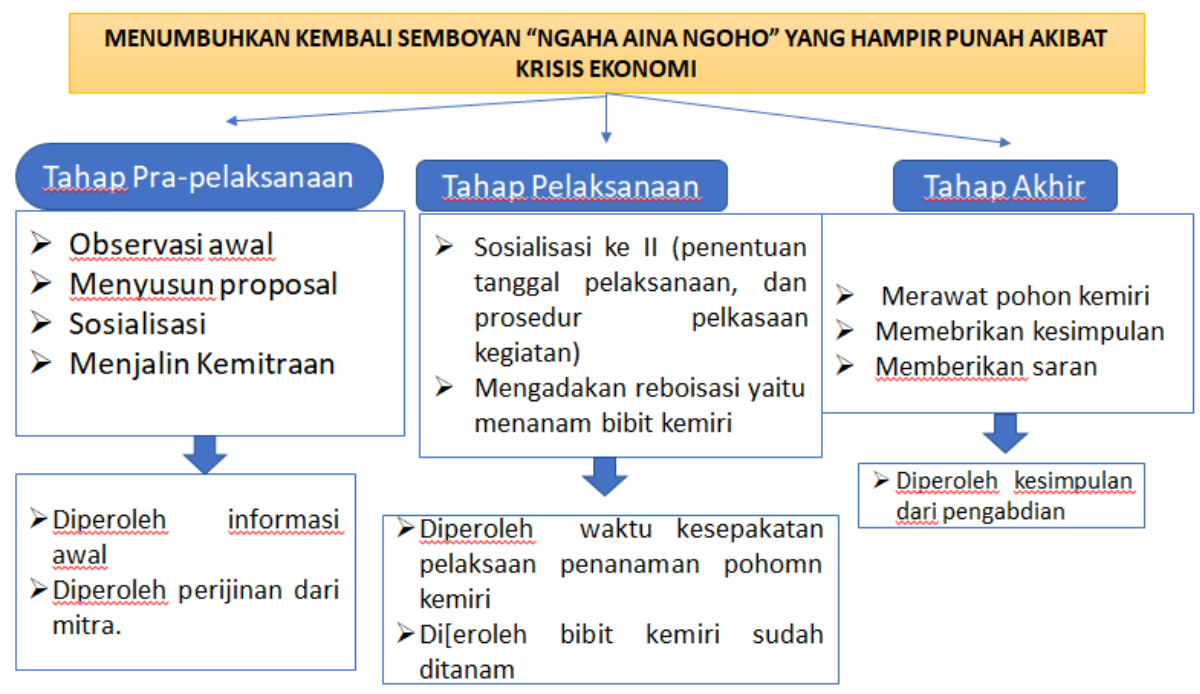


Gambar 1. Metode Pelaksanaan Kegiatan

HASIL DAN PEMBAHASAN

\section{Pelaksanann Kegiatan}

a) Sosialisasi dengan pemuda dan masyarakat desa rora tentang kearifan local dan manfaat kegiatan. Sosialisasi telah dilakukan pada tanggal 21 September 2020, dengan peserta sosialisasi adalah warga desa rora beserta pemuda dan pemudi dari desa rora yang tergabung dalam GBH (Geng Baku Hantam).program ini juga bekerja sama dengan pemuda GBH dan juga kawan sesama mahasiswa yang senantiasa mendistribusikan waktu dan tenaganya untuk sama-sama menyukseskan kegiatan ini.pada kegiatan ini juga kami mengundang aparatur kepolisian untuk mengawal segala kegiatan kamidalam melakukan sosialisasi sekaligus reboisasi di desa rora dan untuk materi sosialisasinya sendiri dibawakan langsung oleh ketua. Dalam sosialisasi ini diberikan materi mengenai makna semboyang "ngaha ajna ngoho" yang sebenarnya dan mengapa mengarifan lokal ini harus Kembali di tumbuhkan dalam diri masyarakat dan anak muda dan dalam sosialisasi inipun memaparkan materi tentang kenapa memilih pohon kemiri sebagai pohon untuk kegiatan reboisasi
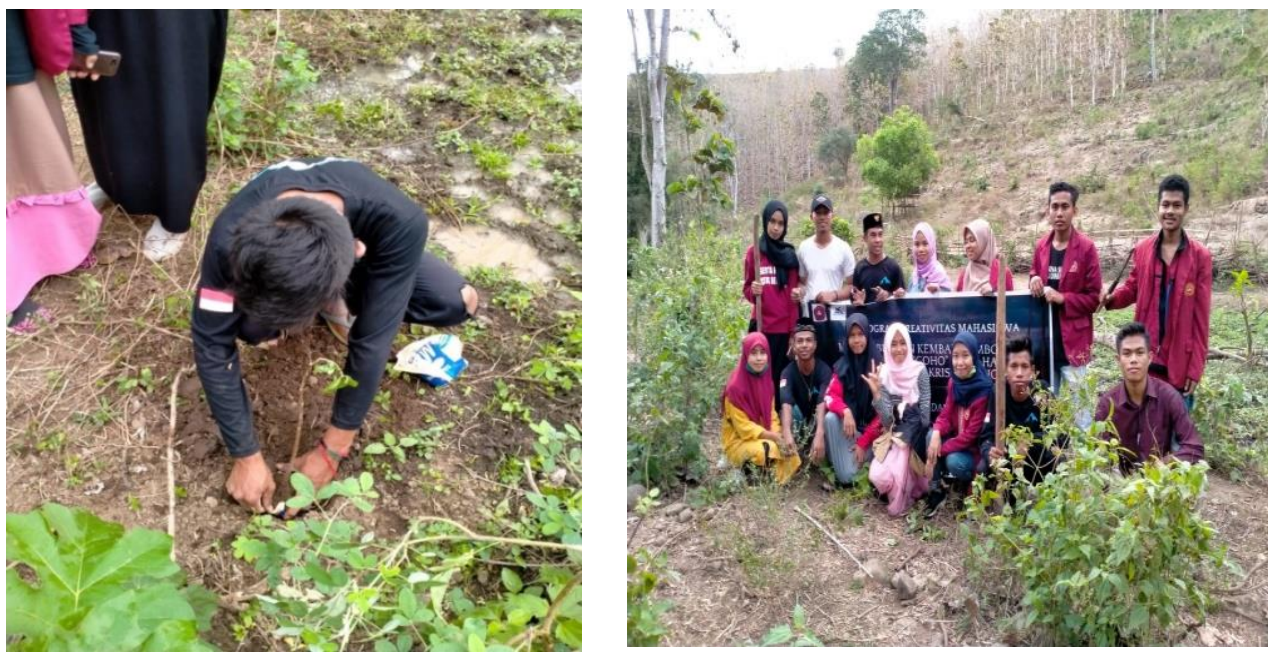

Gambar 3: Kegiatan Reboisasi

Penanaman mohon kemiri di salah satu ladang milik warga yaitu pada tanggal 21 September 2020. Bibit kemiri yang ditanam kurang lebih 50 pohon bibit beserta juga manfaatnya dalam menstabilkan ekonomi.

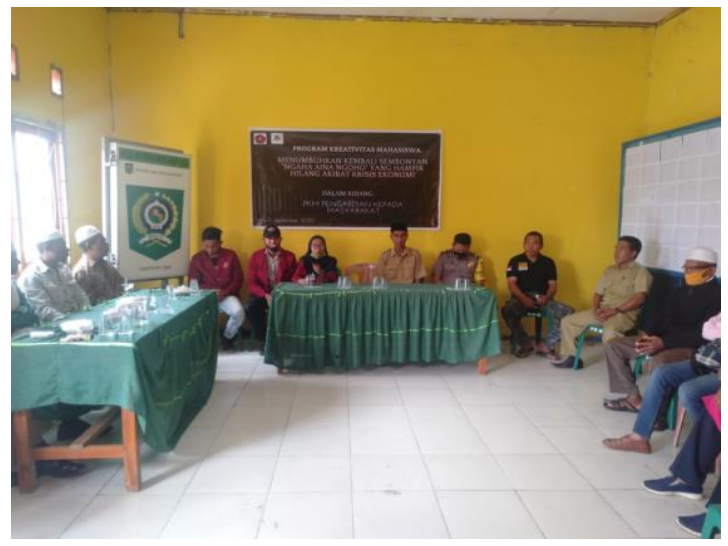

Gambar 2. Sosialisasi di kantor

Desa Rora

b) Setelah terlaksananya kegiatan sosialisasi pemuda setempat langsung aktif dan semangat untuk melakukan reboisasi di daerah yang telah tandus sebagai upaya untuk kembali melestarikan alam yang telah rusak sekaligus menjaga kembali apa yang menjadi kearifan local yang hampir punah dalam kehidupan masyarakat bima dan langkah ini juga sebagai upaya untuk menstabilkan ekonomi yang ada karena jika pohon kemiri yang ditanam ini nanti akan menghasilkan nilai ekonomi tersendiri bagi warga. kemiri. Penanaman pohon kemiri ini dilakukan oleh mahasiswa dan pemuda setempat. Dan setelah kegiatan reboisasi dilakukan diharapkan mampu 
mengembalikan dapat memperbaiki ekosistem yang rusak sehingga mampu mengembalikan unsur hara tanah yang rusak akibat tandusnya hutan yang mengakibatkan kehilangan cadangan air

\section{Kegiatan Akhir}

Setelah dilaksanakan kegiatan penanaman bibit kemiri selanjutnya diadakan perawatan terhadap pohon kemiri yang merupakan kegiatan akhir dari kegiatan ini. Adapun perawatan yang dilakukan pada pohon kemiri yaitu pengecekan dan menyirami pohon kemiri dua kali dalam satu minggu, memagari pohon kemiri dengan menggunakan bambu dan kawat, serta memberikan pupuk.

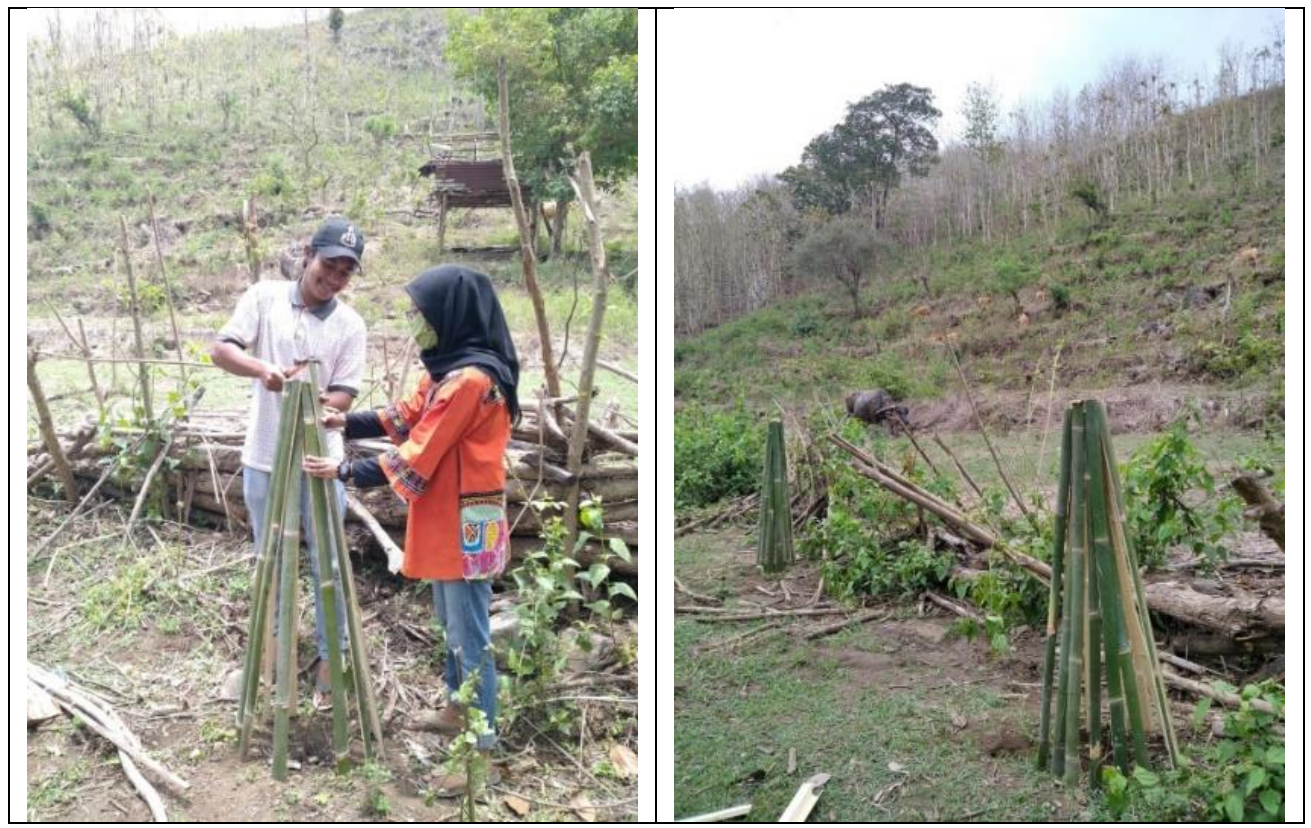

\section{Potensi Keberlanjutan}

Aspek terpenting dalam program pengabdian masyarakat adalah pada potensi keberlanjutan. Keberlanjutan program Kembali tumbuhnya semboyan "Ngaha Aina Ngoho" ini dapat didukung dengan terbentuknya komunitas pelestarian alam yang diberi nama (pecinta alam). Komunitas ini memiliki tugas untuk mengontrol keadaan pohon kemiri yang ditanam sekaligus untuk merawat apa yang ditanam agar tumbuh subur sehingga kegiatannnya tidak sia-sia melainkan harus berjangka Panjang dan mampu memberikan efek positif bagi masyarakat yang ada diwilayah rora.karena antusiasme dari pemuda di desa rora begitu besar maka kami sengaja menjalin komunikasi yang baik dan kemitraan dengan pemudapemudi desa Rora agar bisa sama-sama menjaga apa yang telah dibudidayakan secara Bersama dan bisa mengembangkan hasil panen kemiri kelak agar menjadi suatu produk yang memiliki nilai ekonomi yang tinggi.
Keberlanjutan program Kembali tumbuhnya semboyan "Ngaha Aina Ngoho" juga didukung dengan pendekatan emosional yang dilakukan oleh tim PKM kami dengan pemuda yang ada di desa rora untuk tetap mendukung pelaksanaan program reboisasi. Kerjasama ini juga berbentuk penyampaian informasi atau materi baru tentang keadaan alam sekitar sekaligus keadaan ekonomi di Indonesia yang nantinya akan dibahas dalam diskusidiskusi ringan pada pertemuan mendatang agar pemuda di desa rora tidak hanya monoton pada kelestariaaan alam saja namun mereka dididik agar bisa mengetahui kondisi yang nantinya akan tersinkron dengan sendirinya.

\section{KESIMPULAN}

Terselenggaranya program PKM pengabdian masyarakat menumbuhkan kembali semboyan "Ngaha Aina Ngoho" yang hampir punah akibat krisis ekonomi sebagai upayya merawat kembali kearifan local bima dalam diri masyarakat 
terkhususnya anak muda melalui kegiatan sosialisasi dan reboisasi. Program tersebut terlaksana melalui beberapa rangkaian kegiatan maupun persiapan yang bertujuan untuk menghadirkan Kembali kepedulian masyarakat dan anak muda terhadap alam. Selain itu untuk keberlanjutan program ini maka dibentuknya sebuah komunidas yang bernama 'pencinta alam', yaitu Gerakan muda-mudi dari desa rora, kegiatan diakhiri dengan penanaman bibit kemiri disalah satu gunung yang tandus dan adanya komunitas ini dapat mewadahi pemuda-pemudi desa rora untuk menjaga kelestarian alam. Semoga kegiatan ini tetap berlanjut dan berjangka panjang.

\section{UCAPAN TERIMA KASIH}

Ucapan terima kasih terutama ditujukan kepada kementrian riset dan teknologi yang telah mendanai Program Kreativitas Mahasiswa bidang Masyarakat tahun anggran 2020.

\section{DAFTAR PUSTAKA}

Ismail, a. I., millang, s., \& makkarennu, m. (2019). Pengelolaan agroforestry berbasis kemiri (aleurites moluccana) dan pendapatan petani di kecamatan mallawa. Jurnal hutan dan masyarakat, 11(2), 139-150.

Koji, t. (2000). Kemiri (aleurites moluccana) and forest resource management in eastern indonesia: an eco-historical perspective. International symposium and workshop, "the beginning af the 21st century: endorsing regional autonomy, understanding local cultures, strengthenning natioal integration", hasanuddin university, south sulawesi, august 1-5, 2000. P 1-23.

Manusia, s. D. (2004). Manajemen sumber daya manusia.

Mariati, m. (2013). Maja labo dahu dalam dinamika kehidupan masyarakat bima doctoral dissertation, universitas islam negeri alauddin makassar.

Mulyani, a. Nursyamsi, d, las, i. 2014. Percepatan pengembangan pertanian lahan kering iklim di nusa tenggara. $P e$ ngembangan inovasi pertanian. 7(4).187-198.

Mursalim, i., mustami, m. K., \& ali, a. (2018). Pengaruh penggunaan pupuk organik mikroorganisme lokal media nasi, batang pisang dan ikan tongkol terhadap pertumbuhan tanaman sawi (brassicajuncea). Jurnal biotek, 6(1), 32-45.

Putra, u. W., \& usman, k. (2018) dampak perladangan liar oleh masyarakat di hutan lindung unit pelaksanaan teknis dinas (uptd) kehutanan kecamatan langgudu kabupaten bima. Jurnal silva samalas issn, 2621, 6779.

Salim, e. (2010). Ratusan bangsa merusak satu bumi. Penerbit buku kompas.

Sinaga, r, desrial, wulandari, d. 2016. Karakteristik fisik dan mekanik kemiri (aleurites moluccana wild). Jurnal keteknisan pertanian. 4(1):97-106.

Taiyeb, a. (2017). Evaluasi kesesuaian lahan untuk tanaman kemiri (aleurites moluccana willd.) Pada sistem lahan salo saluwan di kota palu. Forestsains, 14(2), 98-107. 